\title{
WEB-BASED EXPERT SYSTEM OF WHEAT AND CORN GROWTH MANAGEMENT
}

\author{
Xuesong Suo ${ }^{1, *}$, Nan $\mathrm{Shi}^{2}$ \\ ${ }^{1}$ School of Mechanical and Electrical Engineering, Hebei Agricultural University, Baoding \\ 071001, China \\ ${ }^{2}$ College of Life Sciences, Hebei University, Baoding 071002, China \\ * Corresponding author, Address: School of Mechanical and Electrical Engineering, Hebei \\ Agricultural University, Baoding 071001, China; Tel: +86-312-7526475, Fax: +86-312- \\ 7526579, Email: suocedar@163.com
}

\begin{abstract}
Web-based expert system of wheat and corn growth management mainly to put the information of wheat and corn planting on web. It integrated much new knowledge of agriculture including weather, plant protection, expertise, GIS, Internet and computer technology. It provided the information of breed, soil, wheat and crop characteristic for the farmer of different area in Hebei Province on web. Furthermore, it provided all kinds of wheat and corn planting expert systems for different period (insemination, fertilization, remedy, irrigation) of wheat and corn growth. The real time forecasting and management of plant was realized in agricultural production by this system.
\end{abstract}

Keywords: $\quad$ ASP; Precision Agriculture; Expert System; WEB

\section{INTRODUCTION}

As the technical progress of the computer, particularly the continuous development of the network, it makes the exchanges of the information resources to come to an unprecedented fast and convenient. In the agriculture aspect, the large agriculture technologist has already succeeded of carried on the agriculture expert system. Moreover, in recent years a kind of agriculture expert system based on network arose, and because of the large capacity, whole and new of its information has strongly favored of the large farmer. 


\section{THE PURPOSE AND THE MEANING OF THE SYSTEM DEVELOPMENT}

There is very big margin in the level of agriculture infomationization between the developed nation and our country. They mainly performance: the agriculture information equipment is weak; the shared mechanism of the agriculture information standard and resources are lack; especially the valid resources that can be provided to use for farmer; the technologists of the agriculture are lack, and the strength of studies disperses, the level is low; the agriculture information technique application degree is low, far and far, it can't satisfy the request of the new century, the new stage of our country agriculture and village economic development.

To develop the network agriculture expert system, and make use of the Internet to provide the information service and the decision opinion for the farmer is the directions of agriculture infomationization in our country. The Internet has great capacity knowledge, delivers quickly; there are no time and region limiting, so it is the important form of the future information service. It makes use of the information and knowledge obtain, handle, spread, inform to farmer's hand in time and accurately, carry out the agricultural infomationization of production, management and marketing, accelerate the alteration of traditional agriculture and significantly upgrade the agriculture efficiency and management level (Zixing Cai, 2003, Plant R.E., 2001).

\section{TOTAL DESIGN}

\subsection{The development target of the system}

This system has a foundation that many other technique being researched chronically in the agrology, cultivation, meteorology and the agriculture resources efficiently using, applies artificial intelligence technique, and asks for help of the local agriculture expert and plant expert's knowledge, builds up the foundation information database, technique database, model database of the wheat and corn crop control. Studies the intelligence decision of wheat and corn in the each stage of growth develops the wheat and corn crop expert system based on the GIS and WEB, to expand the application of intelligence agriculture, to carry out the service of agriculture information network, to accelerate the infomationization progress of the Chinese agriculture. 


\subsection{The development route of the system}

Collect the space data and attribute data concerning wheat and corn in Hebei;

Establish the data input project that collected from the real growth of wheat, corn and the experience of agriculture technologist;

To establish the wheat and corn crop control strategy (seed, fertilizer, irrigate, medicine);

Make use of the GIS controls to develop program, carry out the issuance of digital map and the crop control decision on the net;

Realize the On-line search of control information concerning wheat and corn.

\subsection{The network project of the system}

That system takes the MapXtreme of the MapInfo company as the technique core, the MapXtreme is the map application server that circulates on the intranet or the internet. It makes the crop control information and resources of wheat, corn can be see on computer map with a variety of form using the MapXtreme technique, carrying out the expert system decision information to outward release, helping the farmer and manager to assign the agriculture resources reasonably (Dongjun, 2000).

\section{FUNCTION OF THE SYSTEM}

\subsection{Design of the function}

The main function of the system is to put the crop and control information of wheat and corn in whole growth course on the web. The system combines weather factor, the knowledge of plant, the expert's experience, geography information system, the Internet technique and computer technique together, provides the breeds condition, growth characteristics, soil type and different weather data in different district of Hebei on the web. In the meantime, it includes the crop management expert system (seeding, fertilization, pesticide and irrigation expert systems) of wheat and corn in each growth stage. It realizes the real-time management and the estimate of crop in whole growth time. It mainly includes four functions: the macroscopical grow information system of wheat in Hebei; 
the macroscopical grow information system of corn in Hebei; the microcosmic grow information system of wheat in Hebei; the microcosmic grow information system of corn in Hebei.

\subsection{The macroscopically grow information system of wheat in Hebei}

\subsubsection{The forecast and decision of wheat's insemination period}

The temperature and sunshine are the main factors that decides the wheat insemination period, so the system applies the function of search for the temperature and sunshine in everyplace in Hebei firstly, then the system can make the diagram of statistical data, it means the different result value with the different color, for example the scarlet means the heat area, the pink color means the low temperature area, the result is very intuitionistic, shown in figure 1. In the decision function of wheat's insemination, the system can make the curve of insemination data based different year and different area, also can offer the text advice of insemination (Ramon, 2004).

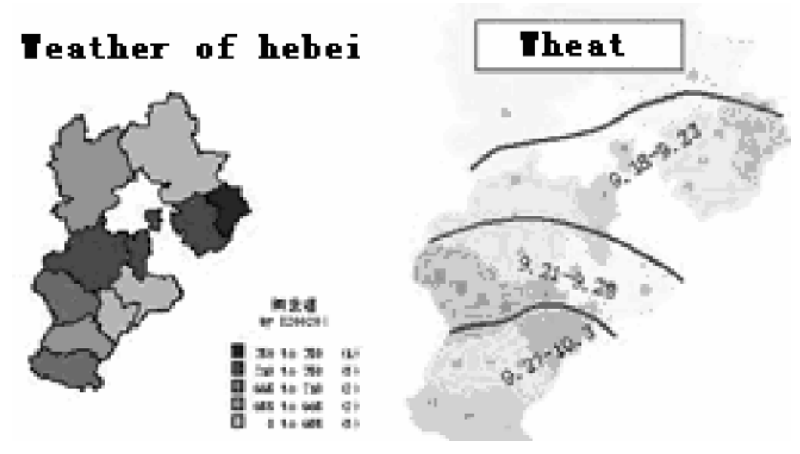

Figure 1. Insemination Pre-decision of Wheat

\subsubsection{The distribute of wheat breed}

System's digital map shows the distributes of different breed with the different icon in each region of Hebei, when the mouse clicks the region, system will show text for each region condition; when the mouse clicks the breed icon, system will show text for each breed, shown in figure 2 . 

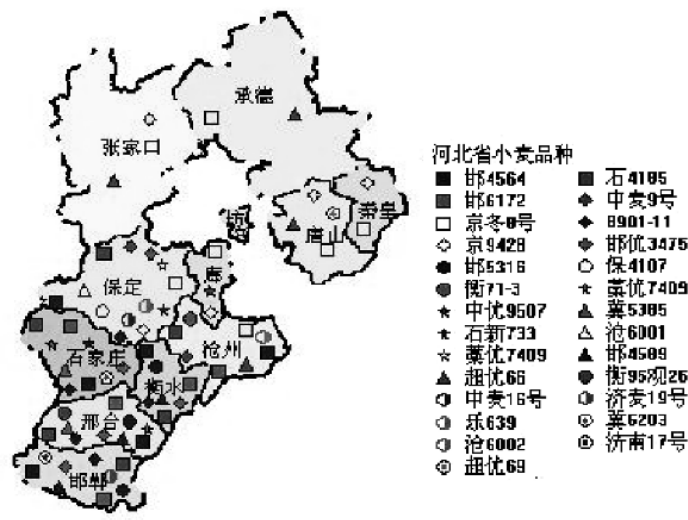

Figure 2. Breed Distribution of Wheat

\subsubsection{The distribute of soil type}

Choose the N, P, the $\mathrm{K}$ the system will make the homologous diagram of statistical data of soil chemical element, in the same methods, it means the different result value with the different color. When you search each area soil type, it will show the corresponding soil chemical element and the detailed text to each type, shown in figure 3.

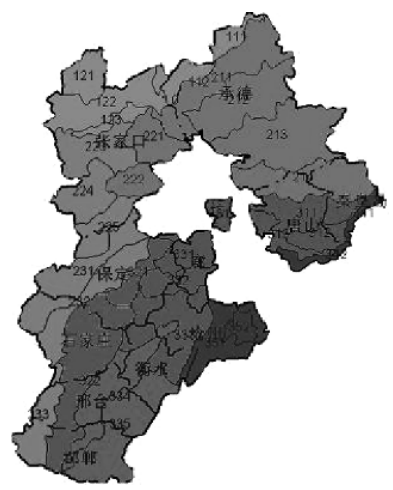

Figure 3. Distribution of Soil Type

\subsubsection{The decision of wheat irrigation}

The wheat irrigation decision according to the dry degree of the earth's surface and precipitation within the same period anciently. Make right irrigation decision according to the change of weather is an important path to carry out high yield. For making the farmer had a clear know to the dry 
degree, the system provided the drought search of each county in Hebei. When the former chooses the year and month, it will make homologous drought statistics data diagram, the different number and color mean the different dry degree, lastly system will present the irrigation opinion with detailed text according to different dry circumstance.

\subsubsection{The predict of wheat diseases and insect pests}

The predict of wheat diseases and insect pests includes the wheat insect diseases search and insect predict, when farmer choose the year and insect category, the system will make corresponding statistics diagram. The predict of wheat diseases and insect pests according to the circumstance of the weather forecast, expert's experience, mathematics model and crop condition, estimate the possible plant diseases and insect pests a month later, result with three kinds of data, index number, popular degree and loss rate, and shows the popular degree (heavy, medium, light, very light, out of fashion) of the plant diseases and insect pests on the digital map with different color conveniently (Zixing Cai, 2003).

\subsection{The macroscopically grow information system of corn in Hebei}

The same to macroscopic wheat information system based WEB in above-mentioned, the system made the detailed statistic to the different corn plant area, the distribution of different breed and output, lastly use the diagram make an auto manifestation on the digital map. At the same time builds up the expert system based WEB, includes the corn irrigation decision and corn plant diseases and insect pests.

\subsection{The microcosmic grow information system of wheat in Hebei}

The microcosmic grow information system of wheat in Hebei takes the Langfang as an example to set up, clicking Langfang on the map of Hebei, then enters that region, then can enter The microcosmic grow information system of wheat in Langfang.

\subsubsection{The wheat insemination predict in Langfang}

In the wheat insemination predict function, the system appears some consultation interfaces of local circumstances, after the farmer responds the corresponding choice, click reload the map, the system will release the 
digital map of wheat insemination predict in Langfang, its form is similar to the macroscopic wheat insemination period estimate, the system will also offer a advise according to the local circumstance. Its result interface such as figure 4 shows.

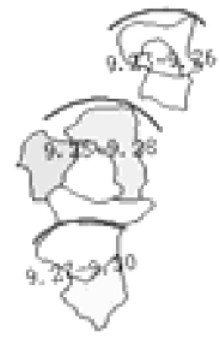

Figure 4. Wheat Insemination in Langfang

\subsubsection{The wheat breed distribution in Langfang}

After the enters this function the system's digital map shows the distributes of different breed with the different icon in each region of Langfang, when the mouse clicks the region, system will show text for each region condition; when the mouse clicks the breed icon, system will show text for each breed. The result interface such as figure 5 shows.

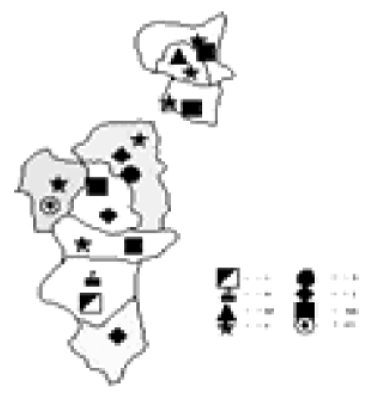

Figure 5. Wheat Breed in Langfang

\subsubsection{The soil productivity distribution in Langfang}

It can statistic the soil productivity distribution in every area of Langfang in the system, and makes caky diagram to release on the digital map, keeping the understanding of view very much to the customer. The result interface such as figure 6 shows. 


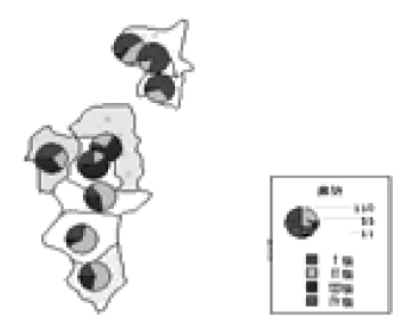

Figure 6. Soil Grade in Langfang

In the meantime the system still carried out the fertilizer decision, the irrigation decision and wheat plant diseases and insect pests predict in Langfang.

\subsection{The microcosmic grow information system of corn in Hebei}

The functions of microcosmic grow information system of corn in Hebei is similar to above, also takes the Langfang as an example, includes the different area of corn plant, the corn species distribution and soil land productivity grade. On the intelligent policy aspect, includes the fertilizer decision, the irrigation decision and wheat plant diseases and insect pests.

\subsection{The total structure of databases}

The total work of the backstage database is divided into four parts, is macroscopic wheat database, macroscopic corn database, microcosmic wheat database, microcosmic corn database. Each part of databases all uses the Access 2000 format. Each parts of databases includes a total information form, the elucidation of the each parts of database is saving in this form, other data save into correspond part forms, to provide the system connects with the Mapinfo map data or other search operation.

\section{THE CONCLUSION AND OUTLOOK}

The network agriculture expert system can be convenient to diffuse agriculture science and technology fastly, having great capacity of information, the instruction is strong, the information is in time and accurate that wins the favor of the large farmer. As the same time, because of the 
booming of agriculture science and technology in our country will necessarily push the network agriculture expert system to a superior level. Again it, the fierce development of the computer hardware also provided the assurance for the healthy development of the expert system. So, the network agriculture expert system will necessarily become the importance part in the agriculture science and technology diffuseness in the future, and continuously develop accompany with the development of the agriculture science and technology.

\section{REFERENCES}

Dongjun Huang, Rui Liu, Songqiao Cheng. The development of expert system based on web [J]. The project and applications of computer, 2000, (9): 124-126.

Plant R.E. An Artificial Intelligence Based Method for Scheduling Crop Management Actions Agriculture System [J]. 2001, 31:127-155.

Ramon M. CU, Roland F. Line. An Expert Advisory System for Wheat Disease Management [J]. Plant disease. 2004, (2): 209-215.

Zixing Cai, Guangyou Xu, Artificial Intelligence: Principles and Applications [M], Qinghua University Press, Beijing, 137-143, 2003. 